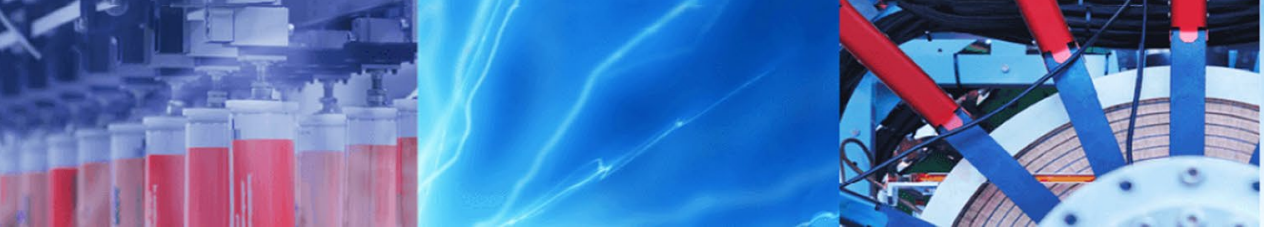

Research Article

\title{
Optimum design of tuned mass damper via PSO algorithm for the passive control of forced oscillations in power transmission lines
}

\author{
Mohammad Hossein Abbasi $^{1} \cdot$ Hamed Moradi $^{1}$ (D)
}

Received: 8 November 2019 / Accepted: 2 April 2020 / Published online: 15 April 2020

(c) Springer Nature Switzerland AG 2020

\begin{abstract}
Transmission lines are prone to external excitations due to their low density and internal damping coefficient. They are vulnerable to some natural events such as wind and rain which may disrupt power transmission. Forced vibration due to external disturbances is one of the most frequent causes of failures in these lines. In this study, effects of tuned-massdampers (TMDs) on reduction of forced vibrations are investigated. A mathematical model for the transmission line is proposed by using mode summation technique combined with the dynamics of the absorbers. Best values for the location, stiffness and mass of the absorbers are found by using Particle Swarm Optimization algorithm (damping coefficients are obtained as zero). The objective of the algorithm is to minimize the line deflection to postpone the failure and the replacement of the lines. Results show that the designed TMDs are efficient in reduction of forced vibrations. Finally, the same procedure is implemented under resonance condition. The designed TMDs lead to a high reduction factor in the line deflection. Similarly, the proposed optimization algorithm can be used in other industrial applications of the flexible cables; under various external excitations.
\end{abstract}

Keywords Transmission lines · Forced vibrations · Linear and nonlinear models · PSO algorithm · Tuned mass damper · Optimum design

\section{Introduction}

Extra-high voltage transmission lines, cable-suspended bridges and mooring cables are examples of extensivelyused suspended cables. Transmission lines are vulnerable to wind-induced oscillations, which may lead to large amplitude oscillations and consequently frequent cause some detrimental influences such as connection failure, fatigue and corrosion of cables and reduction of the lifespan and increase in maintenance costs. Thus, finding a way to suppress cable vibrations is necessary. One way to do so is via passive control methods, which is the main focus of this study.
One source for the external disturbances is wind force [1]. The challenge in studying the behavior of such force is the scarcity of data regarding the wind speed, its frequency and amplitude ranges [2]. Although horizontal or rotational motion induced by the wind is also possible, only cable motion in vertical plane is studied due to its higher importance [1,2]. As an example, the excitation frequency ranges between 0.1 and $1 \mathrm{~Hz}$ and the oscillation amplitudes may exceed $10 \mathrm{~m}$ [1]. These high amplitude vibrations may cause flashover [3, 4]. Moreover, these may lead to high loading stresses on insulators and electricity pylons, raising the risk of mechanical/electrical failures and interruption of the power supply.

Hamed Moradi, hamedmoradi@sharif.edu; hamedmoradi@asme.org | ${ }^{1}$ Department of Mechanical Engineering, Centre of Excellence in Design, Robotics and Automation, Sharif University of Technology, Tehran, Iran. 
The dynamic modelling, design and behavior analysis of power transmission lines are investigated in many studies. Mathematical and experimental analysis of transmission lines vibration [5], natural frequencies and mode shapes determination [6], development of a simple model for wind-induced vibrations [7], aerodynamic and aeroelastic analysis of bundled cables [8], and investigating the aero-elastic behavior of bundle conductors through wind tunnel experiments [9] have been discussed. Moreover, vibration of transmission line conductors under downburst loads [10], free vibrations of suspended cables with flexible supports [11], parametric analysis of large amplitude free vibrations of a suspended cable [12, 13], windinduced vibrations of a pre-stressed aramid anchor cable using a simplified fluid-structure interaction [14], and a comparison of different mathematical models for transmission lines vibrations [15] have been investigated.

Also, a review on dynamic aspects, design and parametric study of transmission lines [16], analysis of an aeroelastic model of a real single transmission line span considering its flexural rigidity of the lattice tower, mass and drag using scaling method [17], large amplitude vibrations of ice-accreted/unaccreted conductors in transmission lines under wind force using eigenvalue analysis [18], and dynamic analysis of transmission lines using finite element method [19] have been presented. Recently, dynamic characteristics of transmission lines under turbulent downburst loading [20], measurement of their vibrations based on a heterodyne method [21], characteristics of the raininduced vibrations [22], an ice-detachment failure model for iced overhead electrical conductors [23], and modelling of the ice shedding propagation with or without spacers [24] have been performed.

Different passive control methods have been suggested to reduce forced vibrations of the power transmission lines. For instance, providing sufficient phase-to-phase spacing between lines to prevent flashover and improving icing and aerodynamic characteristics by using smooth faced conductors have been proposed [1-4, 16, 25]. To mention some more works in the direction of passive control methods, one can refer to the work by Den Hartog [26].

Among passive control approaches, vibration absorber has been widely used to suppress vibrations of transmission lines. The effect of Stockbridge dampers' location on maximum strains [27], dampers design for vibrations caused by Karman vortex shedding [28], effects of mechanical damping to suppress wake-induced flutter of conductors using a non-linear linearized quasi-static aeroelastic analysis [29], design of damping devices based on modal analysis [30,31], optimum design of impedance value in Stockbridge dampers for dead-end spans [32] and vibration control of sagged cables under harmonic excitation [33] have been investigated. Moreover, the effect of bending stiffness on damping properties of the cable with tuned-mass-damper (TMD) [34], design of an optimal damper for bridge stay cables [35], optimum design of damper scheme based on finite element simulations via ANSYS [36], dampers design based on energy balance method [37], vibration control of transmission lines based on the Euler-Bernoulli beam model [38], the effect of selfdamping on Aeolian vibrations [39], using tuned vibration absorbers to alleviate vibrations under wind excitation [40], and vibration control of cables with damped flexible supports [41] have been studied.

Most of early works analyzed the transmission lines locally on its cross section as a two degree of freedom (2DOF) lumped model. This assumption is not valid when a long transmission line is studied, as it is a continuous system and therefore contains infinite number of vibration modes. As the dominating modes are suppressed in the control procedure, other structural modes may be excited, leading to a spill-over problem. Furthermore, many of previous control methods did not act efficiently over a wide range of frequency excitations. They work effectively only around a local range of wind excitations.

In this study, optimum tuned-mass-dampers (TMDs) are designed to reduce the forced vibrations in the presence of wind excitations. The discrete-continuous model of the transmission line and TMDs is presented by using mode summation method. Unlike the previous work [40], that an algorithm was developed based on preliminary principles of optimization; in this paper a more advanced and effective $\mathrm{PSO}^{1}$ optimization algorithm is proposed. Best values for the TMDs' parameters are determined using the PSO algorithm in order to minimize the transmission line deflection. PSO algorithm is known as a good global optimizer [42], therefore this method is followed in this paper. Other optimization methods such as metaheuristic methods [43] are not studied in this paper. Afterwards, the efficiency of the designed TMDs is evaluated over a wide range of wind excitation frequencies and especially around the resonance conditions. Finally, the effect of mistuning is studied, which is one of the most challengeable problems in real application of TMDs $[44,45]$.

Besides motions in the direction of wind force, torsional and horizontal vibration may also happen. However, torsional and horizontal vibrations are less important than vibrations in the direction of the wind force $([7,13,15,28$, $30,34])$. In this study, single strings are considered. Tuned vibration absorbers are designed to reduce forced vibrations of transmission lines. The problem of bundled conductors can be studied through a similar procedure.

\footnotetext{
1 Particle Swarm Optimization.
} 


\section{Continuous model of the transmission line with arbitrary number of tuned-mass-dampers}

\subsection{Dynamic model of the transmission line}

In this part, mathematical model of transmission line is presented. The excitation force is assumed to be produced by the wind and applied on the whole length as a distributed force. The transmission line in this paper is considered as a continuous string system and dynamic model of such systems has been investigated in early works [46]. As tension force plays a more crucial role than bending and gravity in string and cable dynamics, bending and gravity forces are neglected in this study.Kinetic $(T)$ and potential $(V)$ energy of the string are described as:

$T=\frac{1}{2} \int_{0}^{L} \rho(x) \dot{y}^{2}(x, t) d x, V=\frac{1}{2} \int_{0}^{L} T(x) y^{\prime 2}(x, t) d x$

where $\rho(x)$ is the mass per unit length of the string, $T(x)$ is the string tension, $L$ is the string length and $\dot{y}(x, t)=\frac{d y(x, t)}{d t}, y^{\prime}(x, t)=\frac{d y(x, t)}{d x}$ where, $y(x, t)$ is the deflection of the string with respect to the equilibrium profile.

Assuming that the normal modes of the string structure $\phi_{i}(x)$ are known, its deflection at any point $x$ can be expressed as:

$y(x, t)=\sum_{i=1}^{n} \phi_{i}(x) q_{i}(t)$

where $q_{i}(t)$ is the generalized modal coordinate. Substituting Eqs. (2) in (1), using the principle of orthogonal functions, and introducing the generalized mass and stiffness as:

$M_{i}=\int_{0}^{L} \rho(x) \phi_{i}^{2}(x) d x, K_{i}=\int_{0}^{L} T(x) \phi_{i}^{\prime 2}(x, t) d x$

results in the kinetic and potential energy in the configuration of generalized coordinate as:

$T=\frac{1}{2} \sum_{i=1}^{n} M_{i} \dot{q}_{i}^{2}(t) ; V=\frac{1}{2} \sum_{i=1}^{n} K_{i} q_{i}^{2}(t)$

Here, it is assumed that the string tension and mass per unit length are constant along the cable length. Using the Lagrange's equation and considering energy dissipation yields the following equation in generalized modal coordinate [47]: $\ddot{q}_{i}(t)+2 \zeta_{i} \omega_{i} \dot{q}_{i}(t)+\omega_{i}^{2} q_{i}(t)=\frac{1}{M_{i}} \int_{0}^{L} f(x, t) \phi_{i}(x) d x$

where $\zeta_{i}$ is the damping ratio coefficient caused by the effect of air resistance to the vertical motion of the conductor, $f(x, t)$ is the distribution of the wind excitation force over the string length. Furthermore, the natural frequencies, $\omega_{i}$, and mode shapes, $\phi_{i}$, of the string are defined as:

$\omega_{i}=\frac{i \pi}{L} \sqrt{\frac{T}{\rho}} \quad(i=1,2, \ldots)$

$\phi_{i}(x)=\bar{\phi} \sin \left(\frac{i \pi}{L} x\right), \quad \bar{\phi}=\sqrt{\frac{2}{L}}$

Dynamic model of the string is described by Eq. (5). It should be mentioned that in Eq. (6), vibrations are assumed to be calculated with respect to the equilibrium profile of the string.

As it is clear from modeling side, the system shown by Eq. (5) represents the linear model of the cable. In order to take nonlinearities into account, some terms can be added to this model increasing the fidelity of the model. For instance, some equations similar to the following equation can be pursued:

$$
\begin{aligned}
\ddot{q}_{i}(t) & +2 \zeta_{i} \omega_{i} \dot{q}_{i}(t)+\omega_{i}^{2} q_{i}(t)+\alpha_{i} q_{i}^{2}(t)+\beta_{i} q_{i}^{3}(t) \\
= & \frac{1}{M_{i}} \int_{0}^{L} f(x, t) \phi_{i}(x) d x
\end{aligned}
$$

where $\alpha_{i}$ and $\beta_{i}$ are two coefficients chosen in a way that the contribution from nonlinear side is of the same order of the linear part. Since the design and optimization process are difficult in the presence of nonlinearities, the design and optimization are performed in the case of linear system and the performance of TMDs are investigated in the case of nonlinear system.

\subsection{Dynamic model of the combined system}

In this section, dynamic model of the tuned-mass-dampers is investigated and it is coupled with the dynamic of the string.

A schematic view of the transmission line with an arbitrary number of absorbers, name this number $\hat{m}$, is shown in Fig. 1. Each absorber contains mass-spring-damper elements. In the presence of absorbers, a concentrated force is applied on the string at the location of the each absorber. Therefore, Eq. (5) is rewritten to the following equation for the $\mathrm{p}$-th absorber, located at $x=x_{p}$ as (while, $p=1,2, \ldots, \hat{m})$ : 


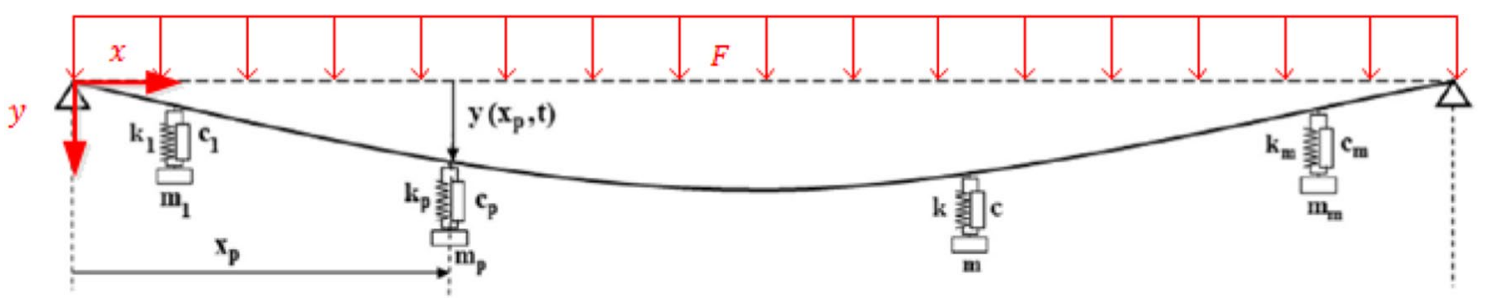

Fig. 1 Schematic view of the transmission line with an arbitrary number of tuned vibration absorbers [40]

$$
\begin{aligned}
\ddot{q}_{i}(t) & +2 \zeta_{i} \omega_{i} \dot{q}_{i}(t)+\omega_{i}^{2} q_{i}(t) \\
= & \frac{1}{M_{i}} \int_{0}^{L} f(x, t) \phi_{i}(x) d x \\
& +\frac{1}{M_{i}} \sum_{p=1}^{m}\left(k_{p}\left[u_{p}(t)-y\left(x_{p}, t\right)\right] \phi_{i}\left(x_{p}\right)\right. \\
& \left.+c_{p}\left[\dot{u}_{p}(t)-\dot{y}\left(x_{p}, t\right)\right] \phi_{i}\left(x_{p}\right)\right)
\end{aligned}
$$

where $k_{p}, c_{p}$ and $u_{p}$ are the $\mathrm{p}$-th absorber's stiffness, damping coefficient and displacement, respectively. In addition to the set of equations used for the string, the following equation describes dynamics of the $p$-th absorber:

$m_{p} \ddot{u}_{p}+c_{p}\left[\dot{u}_{p}(t)-\dot{y}\left(x_{p}, t\right)\right]+k_{p}\left[u_{p}(t)-y\left(x_{p}, t\right)\right]=0$

According to Eqs. (8) and (9), for the $n$ number of modes of the string and the $\hat{m}$ number of the absorbers, there are $n+\hat{m}$ equations and $n+\hat{m}$ unknown variables.

For analyzing absorbers' design procedure, wind excitation is assumed to be independent of location as:

$f(x, t)=f(t)=\bar{F} e^{j \Omega t}$

where $\bar{F}$ and $\Omega$ are the amplitude and frequency of the wind excitation and $j=\sqrt{-1}$. Since any transient function of time can be written in format of its harmonics via Fourier series expansion, only one harmonic of wind excitation is considered in this paper. Thus, the following steps can be also implemented for other cases of wind excitation. Considering steady state responses, the amplitude of coordinates $q_{i}$ and absorbers' displacement $u_{i}$ are presented as below:

$q_{i}(t)=\bar{q}_{i} e^{j \Omega t}, \quad u_{i}(t)=\bar{u}_{i} e^{j \Omega t}$

It should be noted that $\bar{q}_{i}$ and $\bar{u}_{i}$ can attain complex values, so the phase difference relative to the force is hidden in this value. The following equation can be obtained after substituting Eqs. (10) and (11) in the set of Eqs. (8) and (9), as:

$$
\begin{aligned}
& {\left[\omega_{i}^{2}-\Omega^{2}+j\left(2 \zeta_{i} \omega_{i} \Omega\right)\right] \overline{\mathrm{q}}_{\mathrm{i}}} \\
& \quad+\frac{1}{\mathrm{M}_{\mathrm{i}}} \sum_{p=1}^{\hat{m}}\left[\left(k_{p}+j \Omega c_{p}\right) \phi_{i}\left(x_{p}\right) \sum_{s=1}^{n}\left[\overline{\mathrm{q}}_{s} \phi_{s}\left(x_{p}\right)\right]\right] \\
& \quad-\frac{1}{\mathrm{M}_{\mathrm{i}}} \sum_{p=1}^{\hat{m}}\left[\left(k_{p}+j \Omega c_{p}\right) \phi_{i}\left(x_{p}\right) \bar{u}_{p}\right] \\
& =\frac{\bar{F}}{M_{i}} \sqrt{\frac{2}{L}} \frac{L}{i \pi}\left(1-(-1)^{i}\right) \\
& \quad \frac{k_{p}+j \Omega c_{p}}{m_{p}} \sum_{s=1}^{n}\left[\bar{q}_{s} \phi_{s}\left(x_{p}\right)\right]+\left(\Omega^{2}-\frac{k_{p}}{m_{p}}-\frac{j \Omega c_{p}}{m_{p}}\right) \bar{u}_{p}=0, \\
& \quad i=1,2, \ldots, n ; p=1,2, \ldots, \hat{m}
\end{aligned}
$$

Equation (12) represents the combed dynamic system including the transmission line and TMDs under wind excitation. It can be written in the matrix form, $A \underline{X}=B$. $A$ is a full rank matrix of order $(n+\hat{m})$ with elements that are the coefficients of $\bar{q}_{i}$ and $\bar{u}_{p} . \underline{X}$ is a vector that its elements are $\bar{q}_{i}$ and $\bar{u}_{p}(i=1,2, \ldots, n ; p=1,2, \ldots, \hat{m})$ and $B$ is the external force matrix. They are expressed as below. Also, elements of the matrix $A$ are demonstrated in Table 1 in details.

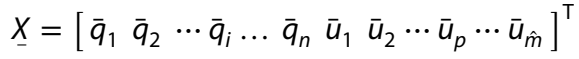

$$
\begin{aligned}
& B=\bar{F} \sqrt{\frac{2}{L}} \frac{L}{\pi}\left[\frac{2}{M_{1}} 0 \ldots \frac{\left(1-(-1)^{i}\right)}{i M_{i}} \ldots \frac{\left(1-(-1)^{n}\right)}{n M_{n}} \quad 0 \quad 0 \quad \cdots \quad 0 \cdots 0\right]^{\top}
\end{aligned}
$$

The $(n+\hat{m})$ natural frequencies of the whole system can be obtained by setting the determinant of $A$ to zero. By simultaneously solving the $(n+\hat{m})$ coupled equations of Eq. (12), one can obtain generalized coordinate $\bar{q}_{i}$ and the amplitude of the absorbers' displacement $\bar{u}_{p}$.

\section{PSO algorithm}

Gradient-based optimization techniques such as quasi-Newton are dependent on the provided initial guess. It is highly plausible that these techniques trap in the local minimizers. Moreover, the investigated problem should be differentiable 


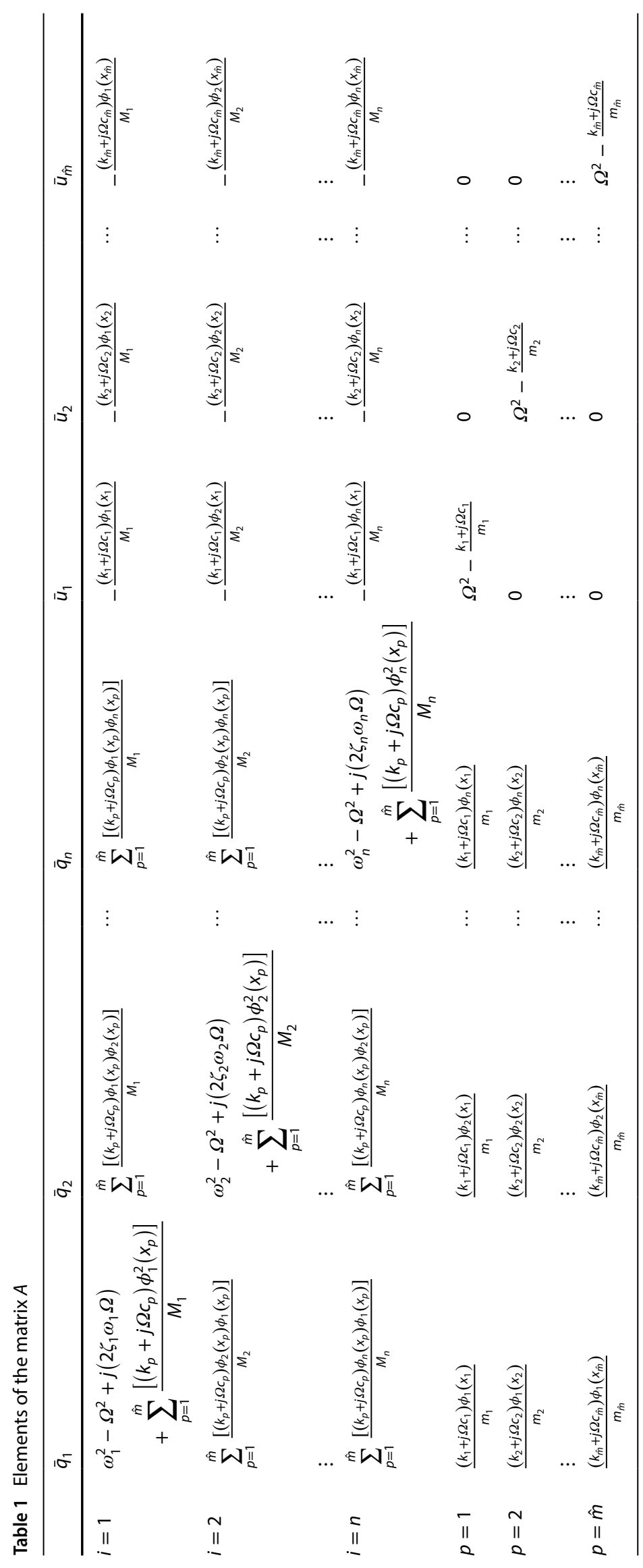




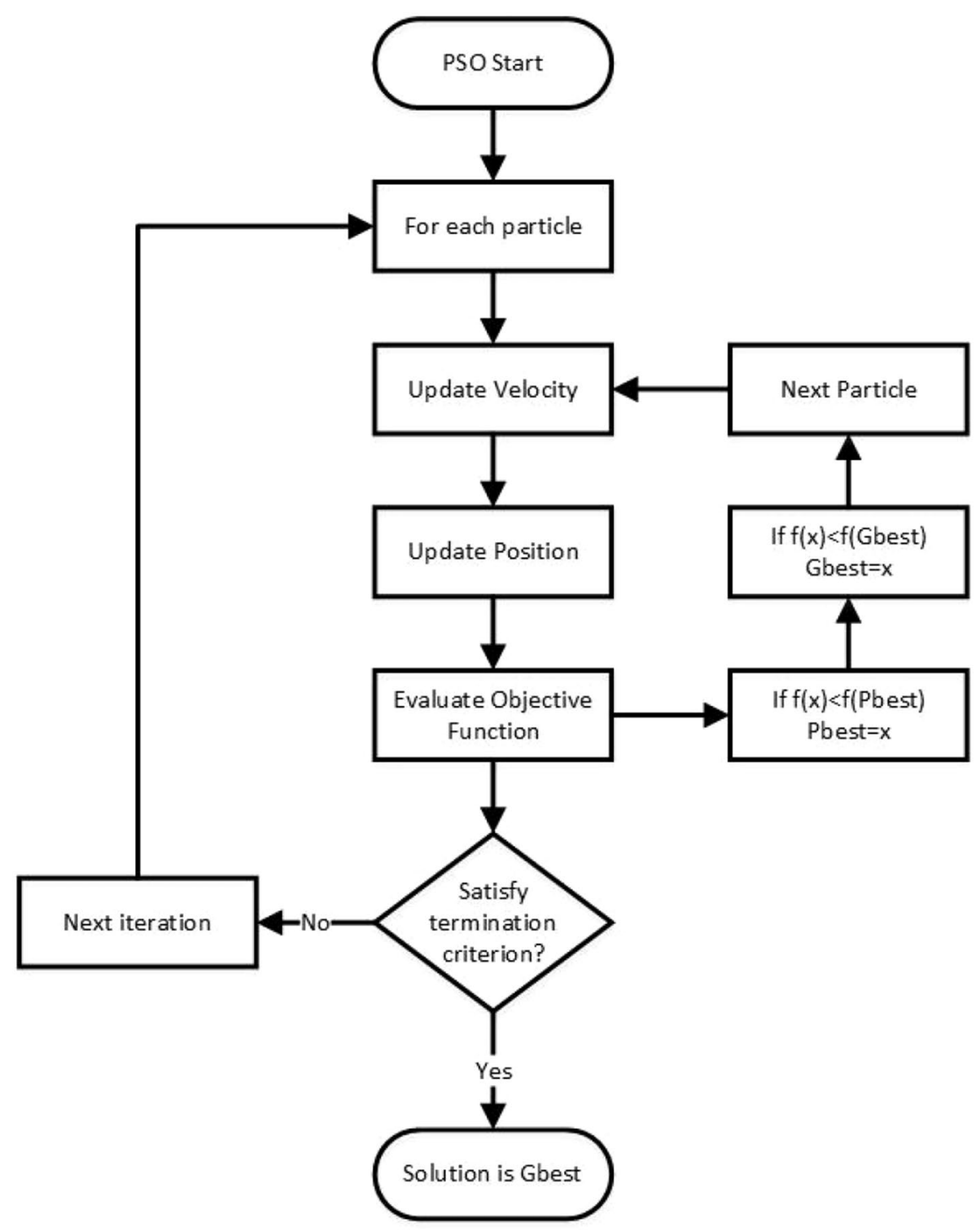

Fig. 2 PSO algorithm flowchart

(for more information in this regard, please refer to [48]). These problems and the ambiguity over the location of the global minimizers lead us to use one of the intelligent optimization techniques. Particle Swarm Optimization (PSO) algorithm is applied for finding the best values of TMDs' properties. PSO algorithm starts with an initial population of random particles indicating the location of each particle. Convergence speed of the process will be influenced by the number of particles. As the number of particles increases, converging to the global minimizers is more probable with the expense of more expensive simulation.

In this method, each particle moves with a certain velocity. The velocity of each particle will be adjusted dynamically based on the particle's objective value and the objective values of its neighboring particles. Particle position in subsequent iterations will be updated regarding the best particle position it has ever achieved $\left(\mathrm{P}_{\text {best }}\right)$ and the best position already taken by other particles $\left(G_{\text {best }}\right)$. After calculating these two quantities, position and velocity of each member will be updated by the algorithm. It should be noticed that the process will terminate as the $\mathrm{G}_{\text {best }}$ convergence is achieved. The flowchart of this kind of optimization is shown in Fig. 2.

PSO algorithm is prepared for the combined problem including the transmission line with arbitrary number of absorbers (for more information about PSO algorithm, refer to [49]). In this process, physical properties of each absorber such as its location, mass and stiffness change simultaneously. The PSO algorithm changes these values in a way that the conductor's deflection gets the minimum 
Table 2 Physical parameters of the case study

\begin{tabular}{llll}
\hline String specification [50] & & Wind specification \\
\hline Mass per unit length & $\rho=5.52 \mathrm{~kg} / \mathrm{m}$ & Amplitude of wind excitation & $\overline{\mathrm{F}}=5 \mathrm{~N} / \mathrm{m}$ \\
String tension & $\mathrm{T}=288 \mathrm{kN}$ & & \\
String length & $\mathrm{L}=300 \mathrm{~m}$ & Frequency of wind excitation & $\Omega=\omega_{1}, \omega_{2}, \omega_{3}, \omega_{4}, \omega_{5}, 3.5 \mathrm{rad} / \mathrm{s}$ \\
Damping coefficient & $\zeta=0.1$ & & \\
\hline
\end{tabular}

possible value. It means that in each iteration, the algorithm chooses an advisable value for the mass, stiffness, damping ratio and the location of the TMDs to minimize a pre-defined function. As the conductor is a continuous system, the deflection is calculated at finite number of points along its length. For instance, the deflection is computed at each $1 \mathrm{~m}$ and the square of the results are added to each other. Thus, the following expression representing a measure for the conductor's deflection (for $\mathrm{N}$ number of elements) is introduced (this function somehow shows the square of the $\mathrm{H}_{2}$-norm of the deflection):

$Z=\sum_{i=1}^{N} y^{2}\left(l_{i}, t\right)$

where $I_{i}$ is the location of element $i$. This objective function shows the $\mathrm{H}_{2}$-norm of the deflection and has a convex characteristic makes it easier for the optimization algorithm to find the best absorber. Since the $\mathrm{H}_{2}$-norm has better convex properties compared to $H_{1}$-norm, this kind of definition has been used. This value changes with changing the time it is calculated in. The objective function is the maximum value of the output of Eq. (14). Let's name the time at which $Z$ gets the maximum value $t^{*}$. Thus the objective function of the PSO algorithm is defined as below:

$Z^{*}=\sum_{i=1}^{N} y^{2}\left(l_{i}, t^{*}\right)$

This value is calculated in the presence and absence of absorbers. The objective of the optimization algorithm is to minimize $Z^{*}$. Through this process, the best values of location, mass, damping and stiffness minimizing $Z^{*}$ are found. In other words,

$\min Z^{*}$

For understanding the performance of the absorber, the function $Z^{*}$ in the presence of the absorbers is compared with this function in the absence of absorbers. Therefore, a reduction index will be introduced as:

$\Re=\frac{Z_{\text {without absorber }}^{*}}{Z_{\text {with absorber }}^{*}}$
This index shows a measure for comparing the value of deflection without absorbers with respect to the case of using absorbers. This optimization procedure can be implemented at a wide range of wind excitation frequencies in a straight forward manner.

\section{Optimum design of TMDs, simulations, results and discussion}

\subsection{Design characteristics of the transmission line}

As mentioned earlier, vibration of transmission line occurs with high amplitude and low frequency at the average wind speeds. Aerodynamic coefficients of transmission lines differ because of its asymmetrical cross section caused by ice. Therefore, vibration will start at a specific wind speed resulting in unstable behavior.

Generally, forced vibration occurs at one of the fundamental vertical modes of the cables. Regarding the maximum sag of the cable, the amplitude of motion corresponding to the first mode is most important. As cable length increases, the probability of oscillations in higher modes also increases. In this paper, the TMDs are designed for various excitation frequencies and performance of the designed TMDs is examined. TMDs' properties in other frequencies can be easily extracted using the interpolation method.

\subsection{Realistic parameters of the conductor and excitation used in simulations}

Properties of an industrial $220 \mathrm{kV}$ single conductor are listed in Table 2 [50]. First harmonics of the wind excitation are considered with uniform amplitude of $\bar{F}=5 \frac{\mathrm{N}}{\mathrm{m}}$ with the frequencies of $\Omega=\omega_{\mathrm{i}}, \quad i=1, \ldots, 5$ and $\omega_{1}<\Omega=3.5 \frac{\mathrm{rad}}{\mathrm{s}}<\omega_{2}$ over the cable length. As a realistic assumption, some model parameters are kept constant

Table 3 First five natural frequencies of the transmission line

\begin{tabular}{llllll}
\hline & $\omega_{1}$ & $\omega_{2}$ & $\omega_{3}$ & $\omega_{4}$ & $\omega_{5}$ \\
\hline Natural frequency value, rad/s & 2.39 & 4.78 & 7.18 & 9.57 & 11.96
\end{tabular}


during optimization process. These are the cable length $\mathrm{L}=300 \mathrm{~m}$, mass per unit length of the string $\rho=5.52 \frac{\mathrm{kg}}{\mathrm{m}}$, cable tension $\mathrm{T}=288 \mathrm{kN}$, and damping coefficient $\zeta_{\mathrm{i}}=0.1$. In addition, five number of modes are considered for the cable for defining its deflection, $n=5$ (these mode shapes are presented in the previous work [40]). According to a mode convergence analysis (which is not presented here for the sake of brevity), the first three modes are sufficient to obtain the solution. However, for conservative reasons, five modes have been used for the analysis. Physical properties of the absorbers such as their stiffness and mass are the same for all absorbers. But their locations differ from each other. Number of absorbers will rise in each case starting from 1 to 3 . Finally, the effect of number of absorbers in minimizing the objective function is studied.

First five natural frequencies of the string are listed in Table 3. It should be noted that natural frequencies of the system with absorbers are slightly higher than those for the string itself.

\subsection{Optimum design of TMDs' parameters}

Results of this section are provided using PSO algorithm for TMDs design. They are presented for wind excitation at resonance frequencies of $\Omega=\omega_{1}, \omega_{2}, \omega_{3}, \omega_{4}, \omega_{5}$ and nonresonance frequency of $\Omega=3.5 \frac{\mathrm{rad}}{\mathrm{s}}$, which lies between the first and second natural frequency. Similar results can be obtained for the other wind excitation frequencies.
First of all, it is assumed that one absorber will be used. The algorithm changes its mass, stiffness, damping and location on a systematic routine. Afterwards, the core program computes the objective function $Z^{*}$ at the critical time $t^{*}$ (as explained in details in Sect. 4). The objective of the algorithm is to minimize the value of $Z^{*}$ in each configuration. The same procedure will be implemented for higher number of absorbers. Afterwards the value of this objective function for different number of absorbers will be compared. For different number of TMDs used, optimum values of the absorbers' parameters such as their location, mass and stiffness are reported in Table 4. It should be mentioned that the damping coefficient in all optimum TMDs attained the zero value during optimization process. However, without damping, results are sensitive with respect to the exact location of the absorber and their corresponding values for the mass and the stiffness. This has been shown in the sensitivity analysis later on.

Number of particles at the PSO algorithm is chosen to 200 according to the previous experience. Increasing the number of particles may prolong each iteration and decreasing the number of particles may result in slow convergence and also trap the local minimum quantity. In this case, most of the simulations are converged after 30 iterations. Each simulation is repeated at least ten times to ensure reaching the global minimum, not local minimum. Moreover, the values of the stiffness, mass and damping coefficient are constrained between $[03000] \frac{\mathrm{N}}{\mathrm{m}},[020] \mathrm{kg}$ and $\left[\begin{array}{ll}0 & 2\end{array}\right] \frac{\mathrm{NS}}{\mathrm{m}}$.
Table 4 Optimum values of the absorbers' parameters for different number of TMDs

\begin{tabular}{|c|c|c|c|c|c|}
\hline & Wind frequency $\Omega$ & Absorber location X (m) & $\begin{array}{l}\text { Absorber } \\
\text { stiffness k } \\
(\mathrm{N} / \mathrm{m})\end{array}$ & $\begin{array}{l}\text { Absorber } \\
\text { mass m } \\
(\mathrm{kg})\end{array}$ & $\mathfrak{R}$ value \\
\hline \multirow[t]{6}{*}{ One absorber } & $\omega_{1}$ & {$[150]$} & 101.4 & 17.6 & 870.2 \\
\hline & $3.5 \mathrm{rad} / \mathrm{s}$ & {$[150]$} & 216.5 & 17.5 & 19.7 \\
\hline & $\omega_{2}$ & [160.3] & 436.1 & 18.3 & 2.5 \\
\hline & $\omega_{3}$ & {$[234.8]$} & 875.9 & 16.8 & 2.4 \\
\hline & $\omega_{4}$ & {$[235.1]$} & 1635.1 & 17.4 & 1.54 \\
\hline & $\omega_{5}$ & {$[241.9]$} & 2621.6 & 17.8 & 1.25 \\
\hline \multirow[t]{6}{*}{ Two absorbers } & $\omega_{1}$ & {$\left[\begin{array}{lll}93.3 & 06.6\end{array}\right]$} & 113.3 & 19.8 & 7218 \\
\hline & $3.5 \mathrm{rad} / \mathrm{s}$ & [92.9 207.1] & 213 & 17.3 & 190.4 \\
\hline & $\omega_{2}$ & [91.7 208.3] & 423.3 & 18.3 & 25.8 \\
\hline & $\omega_{3}$ & {$[92 . .27 .8]$} & 1021.2 & 18.9 & 6.1 \\
\hline & $\omega_{4}$ & {$\left[\begin{array}{lll}55.6 & 244.4]\end{array}\right]$} & 1571.8 & 16.9 & 2.3 \\
\hline & $\omega_{5}$ & [57.5 242.5] & 2530.1 & 17.5 & 2.17 \\
\hline \multirow[t]{6}{*}{ Three absorbers } & $\omega_{1}$ & {$\left[\begin{array}{llllll}65.4 & 150 & 234.6\end{array}\right]$} & 114.4 & 20 & $1.5 \times 10^{17}$ \\
\hline & $3.5 \mathrm{rad} / \mathrm{s}$ & {$\left[\begin{array}{llllll}65.4 & 150 & 234.6\end{array}\right]$} & 151.7 & 12.4 & $2.2 \times 10^{13}$ \\
\hline & $\omega_{2}$ & {$\left[\begin{array}{llll}65.5 & 150 & 234.5\end{array}\right]$} & 366.3 & 16 & $1.6 \times 10^{12}$ \\
\hline & $\omega_{3}$. & {$\left[\begin{array}{llll}65.4 & 150 & 234.6\end{array}\right]$} & 953.9 & 18.5 & $3 \times 10^{11}$ \\
\hline & $\omega_{4}$. & {$\left[\begin{array}{llll}65.4 & 150 & 234.6\end{array}\right]$} & 1830.9 & 20 & $1.6 \times 10^{10}$ \\
\hline & $\omega_{5}$ & {$\left[\begin{array}{llll}65.4 & 150 & 234.6\end{array}\right]$} & 1801.7 & 12.6 & $2.7 \times 10^{8}$ \\
\hline
\end{tabular}



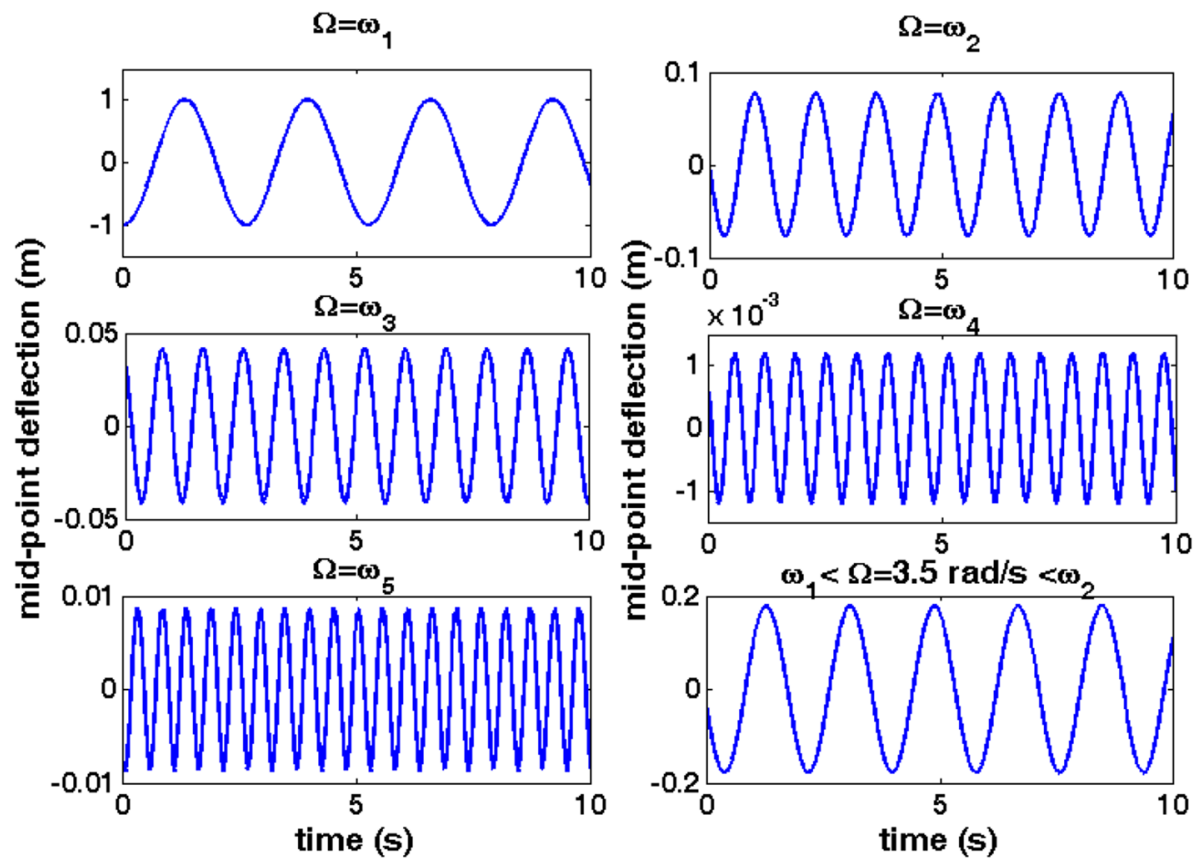

Fig. 3 Mid-point deflection of the transmission line under different wind excitation frequencies—-without using TMDs

\subsection{The effect of optimum TMDs in suppression of vibrations for a wide range of wind excitation frequencies}

First of all, time history of the midpoint deflection of the transmission line (without using TMDs) is shown in Fig. 3. This figure contains the time responses to $\Omega=\omega_{1}, \omega_{2}, \omega_{3}, \omega_{4}, \omega_{5}, 3.5 \frac{\mathrm{rad}}{\mathrm{s}}$. Also, the maximum deflection of the transmission line under different wind excitation frequencies is listed in Table 5.

For suppressing the transmission line vibration, TMDs are used. Different number of absorbers is used to evaluate the effectiveness of number of absorbers. As it is clear, higher number of absorbers leads to both smaller value of objective function and higher expenses. There should be a balance between these two factors. Also, it should be noticed that there is no limitation on absorbers' locations to be symmetric. Optimum physical properties for different numbers of TMDs under various wind frequencies are listed in Table 4. The reduction index $\mathfrak{R}$ is also displayed in Table 4. As it is observed and physically expected, the optimum absorber's stiffness and mass value have the relation of $\Omega \approx \sqrt{\frac{k}{m}}$. Mid-point deflection of the cable in the presence of different number of absorbers is demonstrated in time domain in Fig. 4; in analogy to the case without absorber represented in Fig. 3.

Time responses of the transmission line without the absorbers under different wind excitations are examined. Its deflection at the critical time $t^{*}$ is shown in Fig. 5. This figure demonstrates the cable deflection along the length at the mentioned critical time. Moreover, the transmission line deflection at the critical time, and after implementation of TMDs is shown in Fig. 6. Comparing the Figs. 5 and 6 reveals the high efficiency of using absorbers, especially three absorbers. Increasing the number of absorbers in this problem seems useless because the three absorbers lead to a very high value of reduction index, $\Re=1.5 \times 10^{17}$ at $\Omega=\omega_{1}$. The maximum deflection of the transmission line in the absence and presence of the absorbers is also listed in Table 5.

For a more convenient comparison of the results, the mid-point deflection in the absence and presence of the
Table 5 Maximum deflection of the transmission line in different simulations

\begin{tabular}{lllllll}
\hline $\begin{array}{l}\text { Wind excitation } \\
\text { frequency, rad/s }\end{array}$ & \multicolumn{6}{l}{ Maximum deflection $(\mathrm{m})$} \\
\cline { 2 - 7 } & $\omega_{1}$. & $3.5 \mathrm{rad} / \mathrm{s}$ & $\omega_{2}$. & $\omega_{3}$ & $\omega_{4}$ & $\omega_{5}$ \\
\hline Without absorber & 1.01 & 0.18 & 0.077 & 0.042 & 0.018 & 0.011 \\
One absorber & 0.041 & 0.051 & 0.06 & 0.034 & 0.019 & 0.012 \\
Two absorbers & 0.014 & 0.014 & 0.014 & 0.02 & 0.011 & 0.01 \\
Three absorbers & $2.07 \times 10^{-12}$ & $4.6 \times 10^{-8}$ & $6.1 \times 10^{-8}$ & $7.8 \times 10^{-8}$ & $1.15 \times 10^{-7}$ & $5.33 \times 10^{-7}$ \\
\hline
\end{tabular}




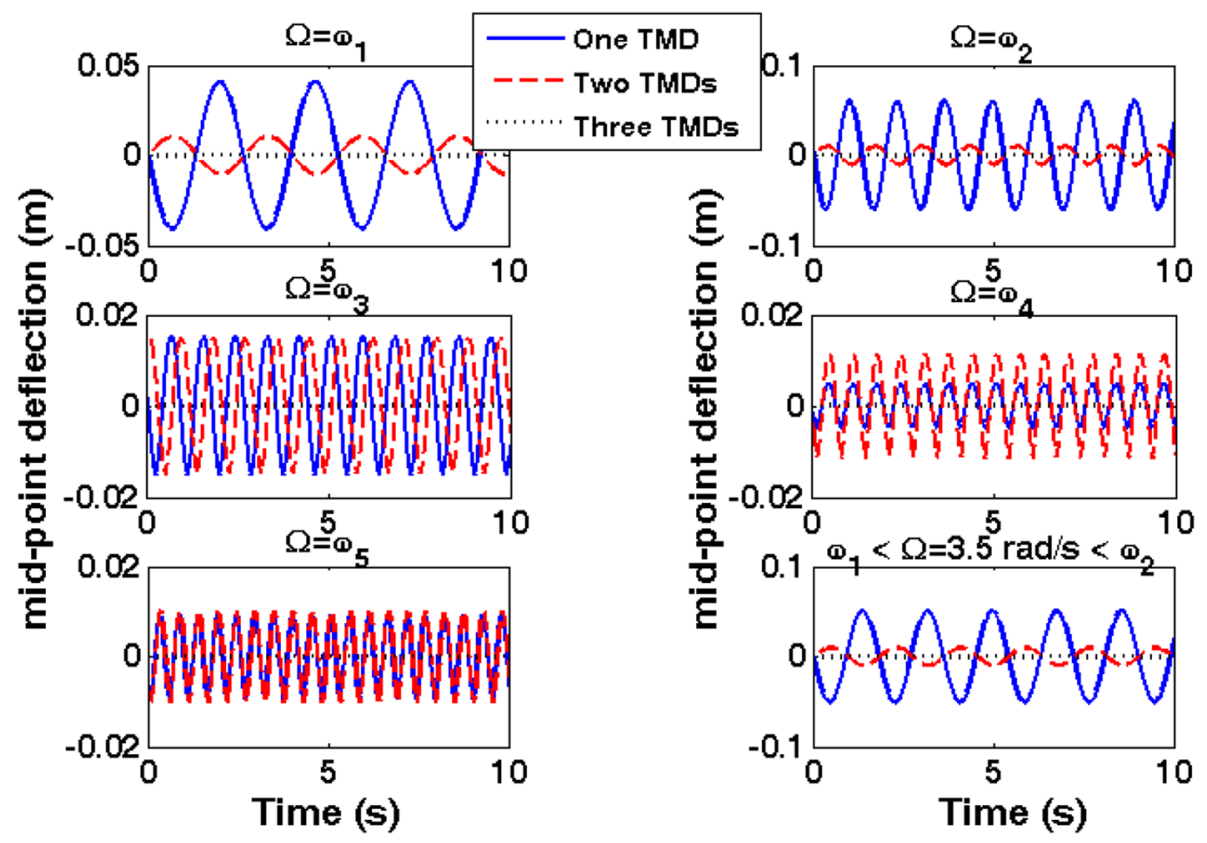

Fig. 4 Mid-point deflection of the transmission line under different wind excitation frequencies-using one TMD (solid blue line), two TMDs (dashed red line), and three TMDs (dotted black line)
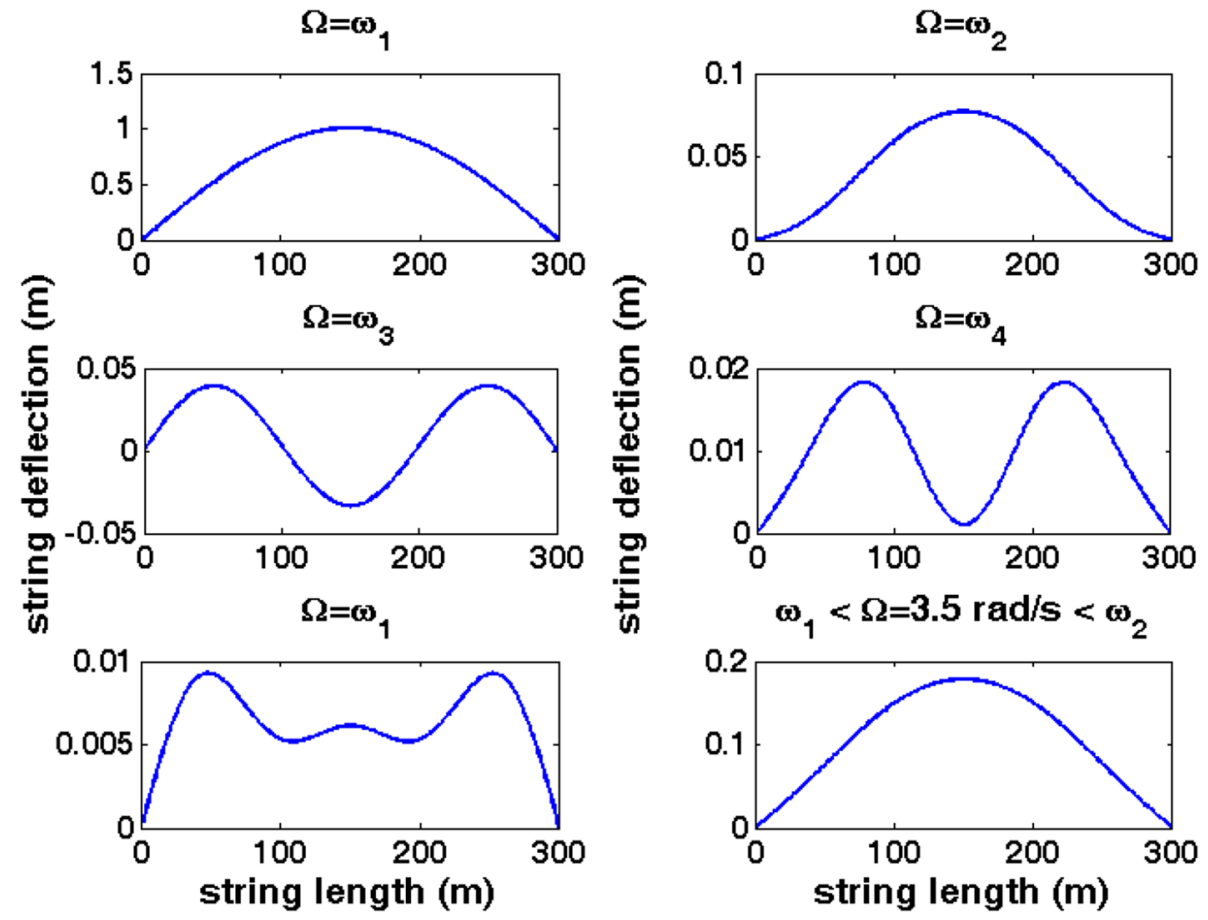

Fig. 5 Transmission line deflection at the critical time $\left(\boldsymbol{t}^{*}\right)$ under different wind excitation frequencies—without using TMDs

best configuration of the TMDs (two and three absorbers) under wind excitation frequencies of $\Omega=\omega_{5}$ (where the minimum reduction index occurs), and $\Omega=3.5 \frac{\mathrm{rad}}{\mathrm{s}}$ (the non-resonance condition), are shown in one frame in Fig. 7.
As it is obvious from the results, using three TMDs leads to the best result. The maximum reduction index and minimum deflection occur at this case. Moreover, as another advantage, the location of the absorbers remains the same 

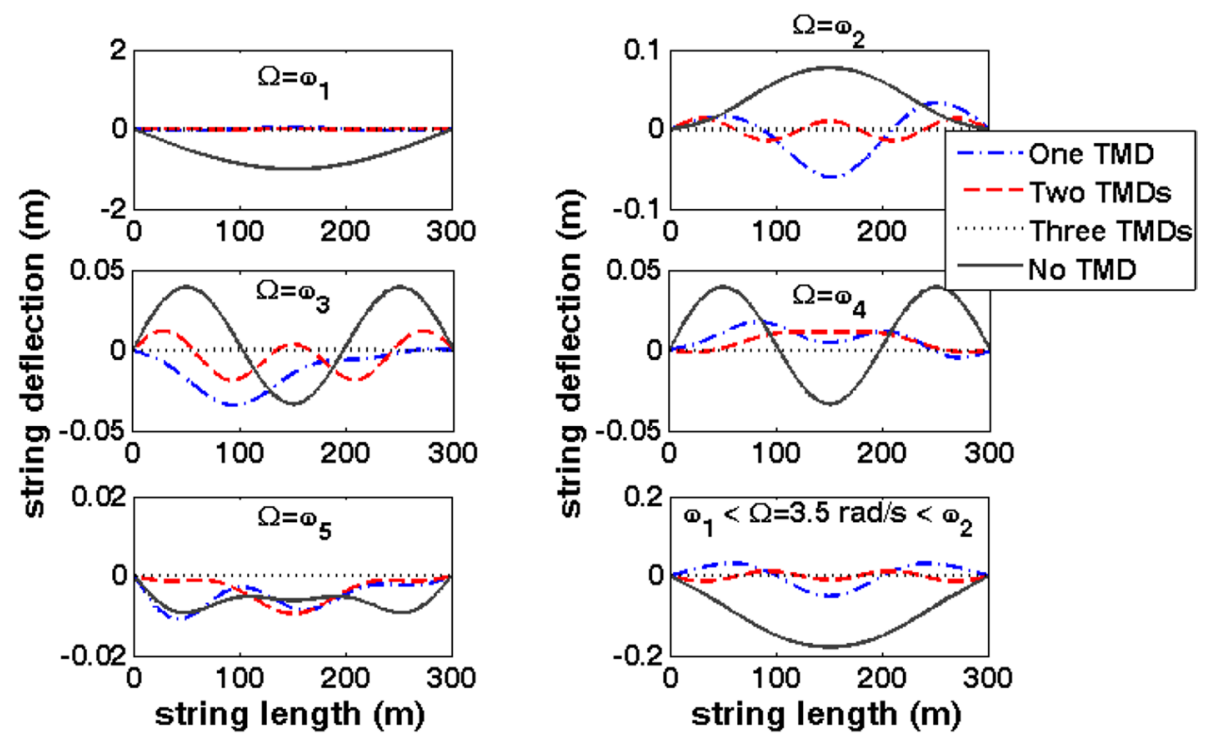

Fig. 6 Transmission line deflection at the critical time $\left(\boldsymbol{t}^{*}\right)$ under different wind excitation frequencies-using one TMD (dotted-dashed blue line), two TMDs (dashed red line), and three TMDs (dotted black line), no TMD (solid gray line)

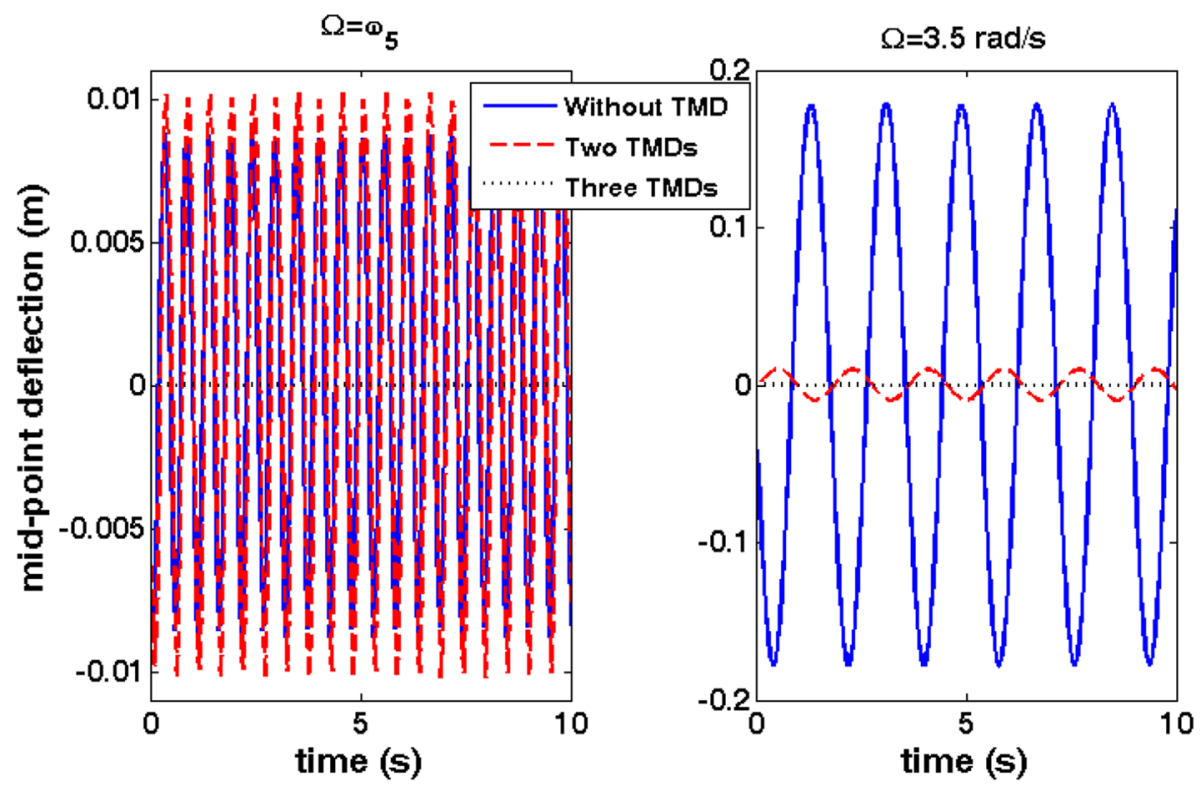

Fig. 7 Mid-point deflection of the transmission line under two specific wind excitation frequencies, $\boldsymbol{\Omega}=\boldsymbol{\omega}_{5}$ (left) and $\boldsymbol{\Omega}=3.5 \frac{\mathrm{rad}}{\mathrm{s}}$ (right) without TMD (solid blue line), two TMDs (dashed red line), and three TMDs (dotted black line)

as the frequency changes. Therefore, due to these constant locations, assembling the three TMDs is more comfortable.

Figure 8 shows the maximum deflection of the transmission line relative to the wind excitation frequencies in a logarithmic chart. Results in the absence and presence of the TMDs (using two and three absorbers) are presented in one figure. This shows how effective the designed TMDs are. It is clear that using three TMDs results in very small deflections even in high excitation frequencies. As it is observed, the TMDs are more effective in suppression of vibrations at low excitation frequencies (corresponding to the dominant modes of the transmission line). Also, using three TMDs clearly leads to a higher efficiency.

The most efficient configuration will happen in the case of using three TMDs. Optimum values of the location, mass and stiffness of the three TMDs under various wind 


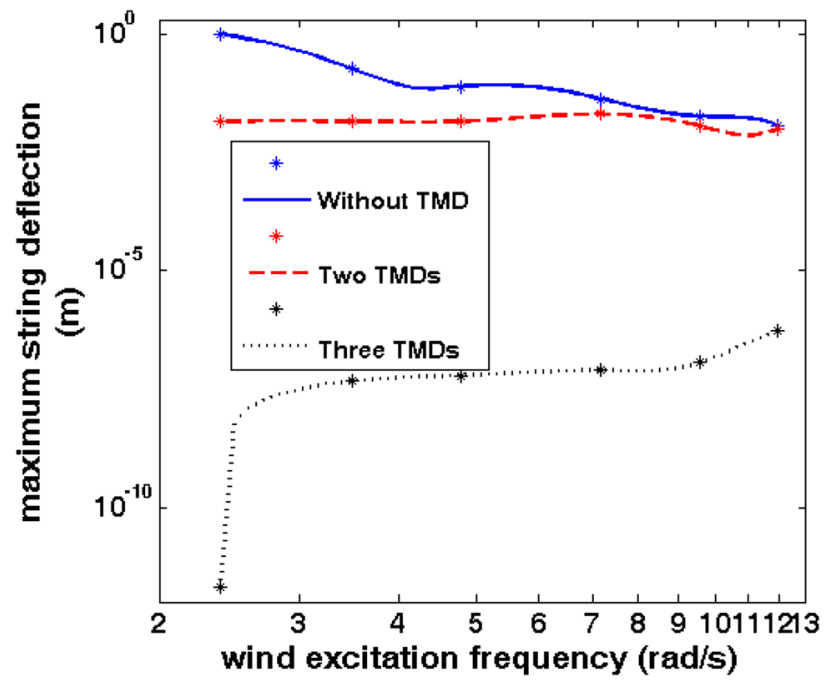

Fig. 8 Maximum deflection of the transmission line under various wind excitation frequencies-without TMD (solid blue line), two TMDs (dashed red line), and three TMDs (dotted black line)

excitation frequencies can be calculated from the previous results. These optimum parameters can be extracted from the 2D charts displayed in Fig. 9 (as the reference diagrams in practice).
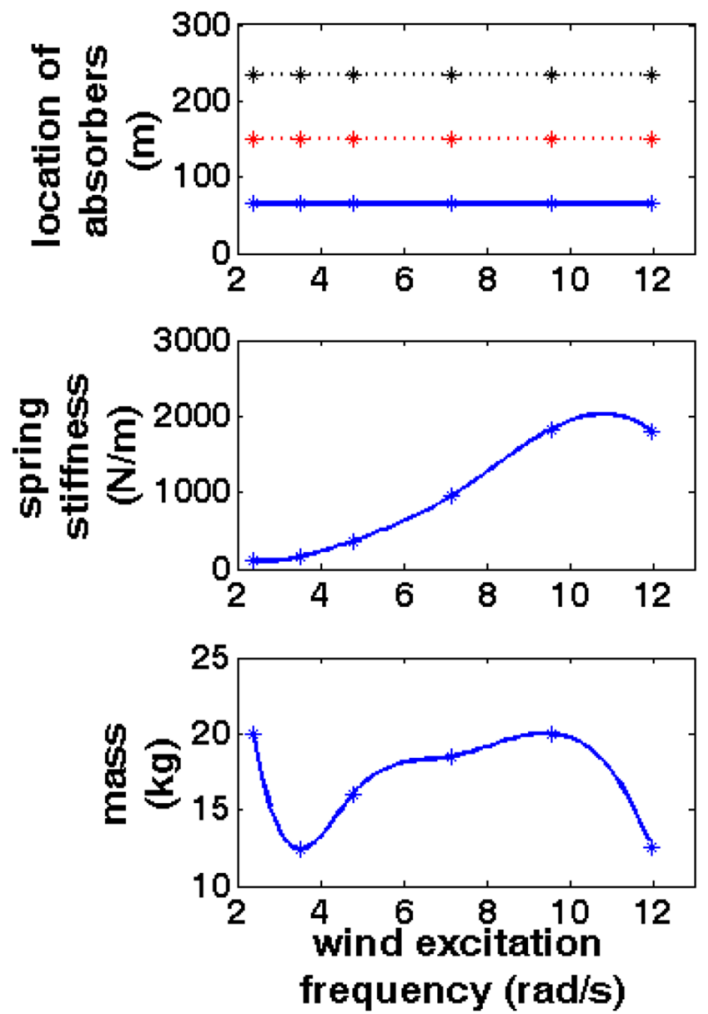

Fig. 9 Spline-interpolated diagrams for finding the best values for the location, mass and stiffness of the TMDs for suppressing the oscillations at different wind excitation frequencies rather than those addressed in the context
Obviously, TMDs act efficiently in suppression of conductor vibrations; especially for forced vibrations which occurs in the resonance condition. Similarly, the absorber can be designed for other excitation frequency ranges. However, in this paper, a dominant frequency range is assumed for the wind excitation which can be obtained from the climatic data.

As a final remark, it should be mentioned that for a more comprehensive analysis, using one, two and three absorbers are studied for different resonance conditions (as presented in Table 4). In all cases, using just one absorber is also good; but the amount of reduction ratio is low. For instance, $\Re=2.5,2.4,1.54,1.25$ under the conditions of $\Omega \approx \omega_{2}, \omega_{3}, \omega_{4}, \omega_{5}$, respectively. To obtain the higher values of reduction ratio, more absorbers are used. As it is observed in Table 4, very large values of reduction ratio are obtained when three absorbers are applied.

For the case when the wind amplitude changes with time, i.e., $F$ in Eq. (10) is varying with time randomly, the TMDs still work efficiently. For the case of three absorbers with the wind frequency $\omega_{1}$ and maximum amplitude of 5 , the reduction index remains around $10^{5}$.

Remark The physical properties of the absorbers are obtained via the optimization process for each wind frequency separately. This is the reason for obtaining the negligibly small values for the deflection of the string in case of three absorbers. However, in practice, it is impossible to observe exactly all the values presented in Table 4 and

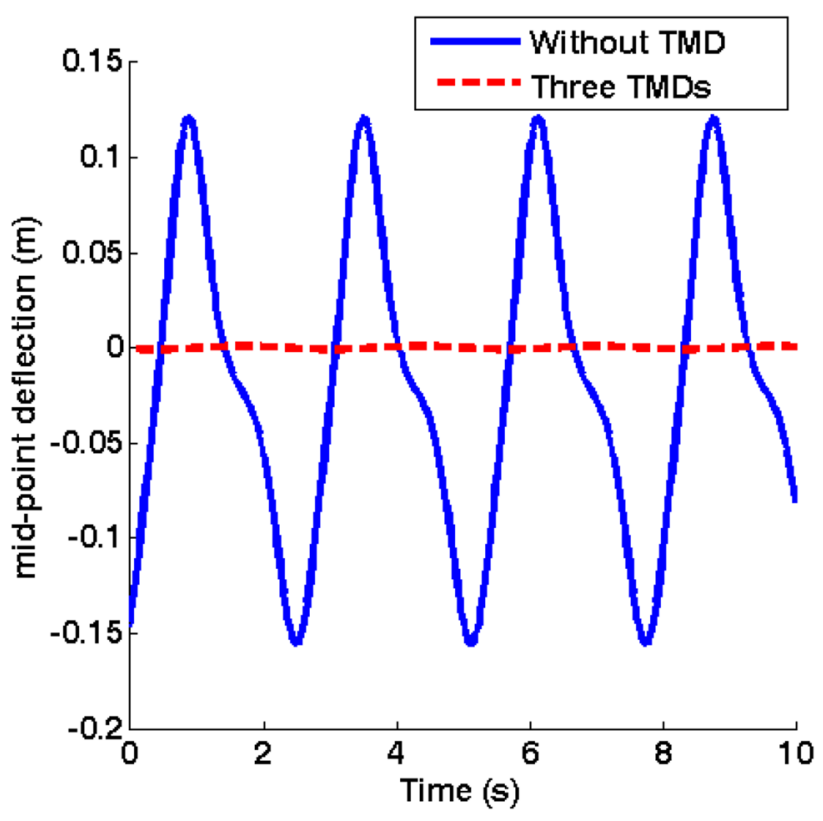

Fig. 10 Mid-point deflection of the nonlinear transmission line under specific wind excitation frequency, $\boldsymbol{\Omega}=\boldsymbol{\omega}_{1}$-without TMD (solid blue line), and with three TMDs (dashed red line) 


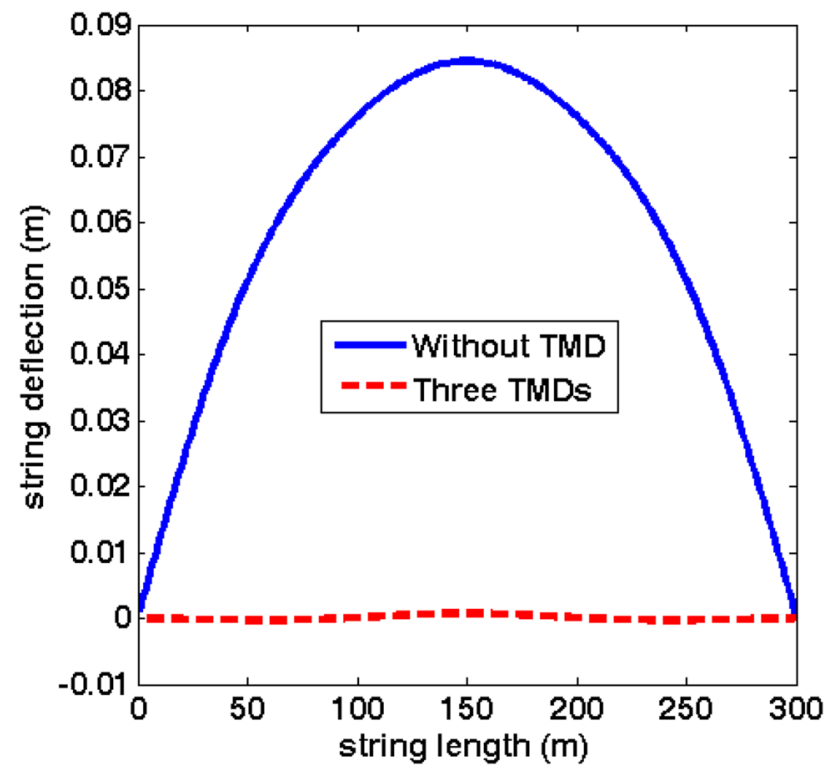

Fig. 11 Nonlinear transmission line deflection at the critical time $\left(t^{*}\right)$ under specific wind excitation frequency, $\boldsymbol{\Omega}=\boldsymbol{\omega}_{1}$-without TMD (solid blue line), and with three TMDs (dashed red line) errors in, e.g., mass weight and the location of the installation of the absorbers always exist. These uncertainties will dramatically reduce the reduction factor even in the case of three absorbers. The following section is provided to analyze these effects.

\subsection{Sensitivity analysis on the optimized variables}

The mistuning effect is one of the most challengeable problems in real application of TMDs [44, 45]. As the constructed and installed TMDs may differ from the optimized ones in the location, mass and stiffness of the spring, sensitivity analysis is inevitable. Here, these values are varied over a specific range with respect to the optimized values and results are reported. For the first resonance frequency and considering $10 \%$ variation in the mass, stiffness and location of the TMD $\left(m=22 \mathrm{~kg}, K=104 \frac{\mathrm{N}}{\mathrm{m}}, x=\left[\begin{array}{lll}70 & 150 & 240\end{array}\right] \mathrm{m}\right)$, the reduction index decreases from $1.5 \times 10^{17}$ to 12.5 . Although this amount of error in the installation and construction of the TMD is high, still the TMD works efficiently and reduces the string deflection (more than ten times).

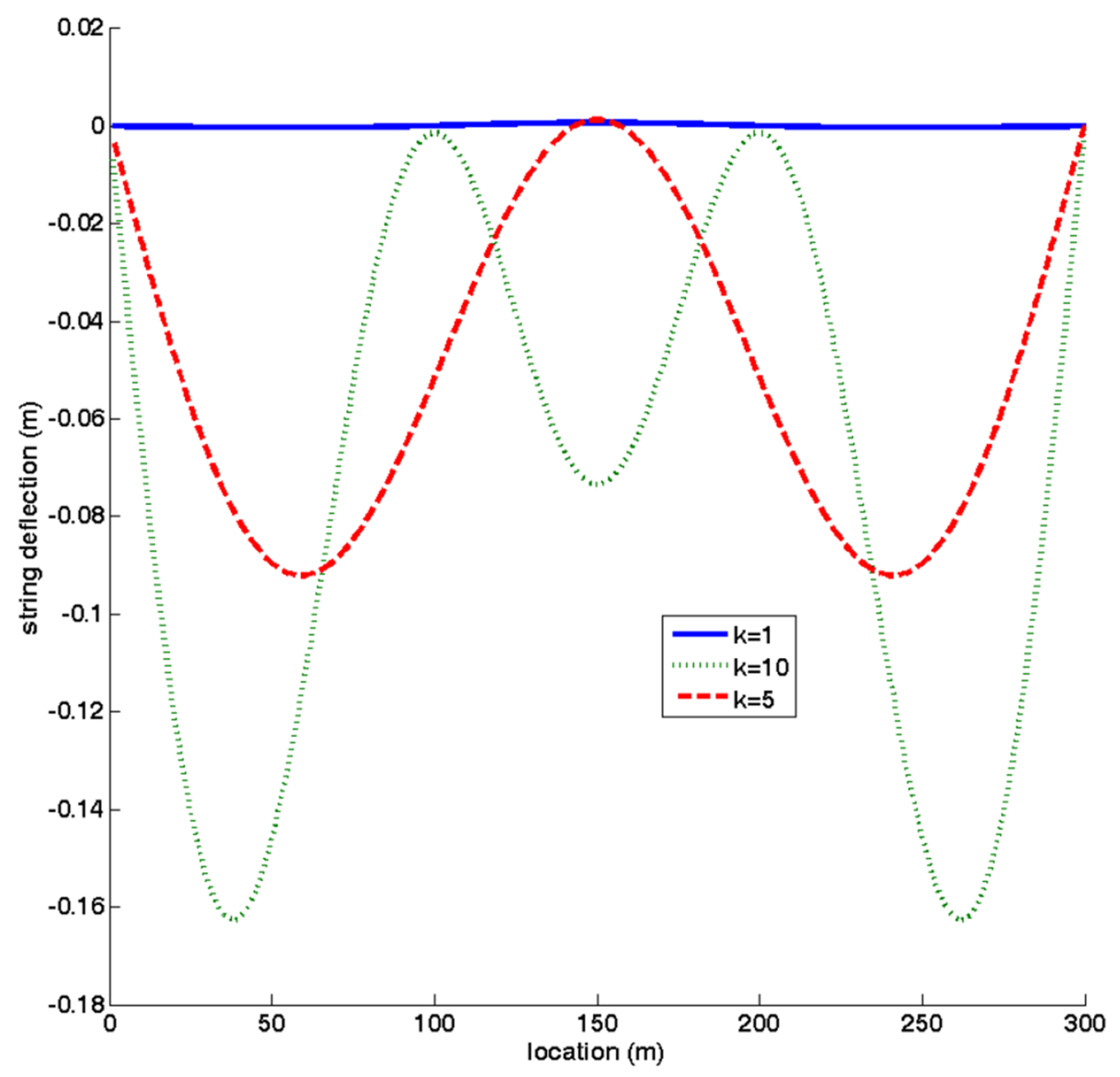

Fig. 12 Nonlinear transmission line deflection at the critical time $\left(\boldsymbol{t}^{*}\right)$ under specific wind excitation frequency, $\mathbf{\Omega}=\boldsymbol{\omega}_{\mathbf{1}}$-with three TMDs and for various values of structural nonlinearity coefficients $\alpha_{i}=5.72 \boldsymbol{k}, \boldsymbol{\beta}_{\boldsymbol{i}}=5.72 \boldsymbol{k} ; \boldsymbol{k}=1,5,10$ 


\section{Evaluation the effect of optimum TMDs on a nonlinear model of the cable}

It should be mentioned that in this section, a well-common nonlinear model is considered to see if the optimal designed TMDs can work effectively in the presence of model structural nonlinearities. For instance, the value of these parameters can be assumed as a factor of the value of $\omega_{i}^{2}$, however their physical units differ from $\omega_{i}^{2}$. For the sake of brevity, only the resonance condition of $\Omega=\omega_{1}$ is investigated. Other cases can be easily simulated in the same way. Comparison of mid-point string deflection with and without the optimal TMDs is presented in Fig. 10, while the string deflection at the critical time $t^{*}$ is shown in Fig. 11.

In addition, the effect of designed TMDs in vibration suppression of nonlinear model with various values of structural nonlinearity $\alpha_{i}, \beta_{i}=k \omega_{i}^{2}$ while $k=1,5,10$ is shown in Fig. 12. It should be mentioned that the cases $k=5,10$ (theoretical large values of nonlinear coefficients) may not occur in reality. But, to show the effectiveness of designed TMDs for the large theoretical values of nonlinear terms, these cases are also studied.

Obviously, the optimum TMDs still works efficiently even when there is nonlinearity in the model. This shows the robustness of the optimum TMDs performance in the presence of model structural nonlinearities.

\section{Conclusions}

Optimum design of tuned-mass-dampers (TMDs) as a passive control approach to reduce the forced vibrations of transmission lines is studied. Dynamics of the cable and the TMDs are combined to build the mathematical model of the combined system. TMDs are designed to suppress the vibrations under various wind excitation frequencies. Using the PSO algorithm, optimum values of the TMDs' properties including their location, mass and stiffness are obtained such that the transmission line deflection is minimized globally. Simulation results are presented both in the time and frequency domains.

Furthermore, the reduction index is defined. This value shows the ratio of the conductor deflection without absorbers to the case with absorbers. In this study, there is no limitation on the optimum locations of the TMDs to be symmetric with respect to the conductor centerline. TMDs are so efficient in vibration reduction of conductors under various wind excitation frequencies, especially under the resonance conditions. Also, it is observed that the TMDs are more effective in suppression of forced vibrations at low excitation frequencies (corresponding to the dominant modes of the transmission line).

In addition, optimum design of TMDs is done over a wide range of harmonic excitations in a discrete manner. It is observed that very large reduction indices are obtained when three TMDs are implemented. A 2D reference diagram is presented for choosing the optimum values of the absorbers' location, mass and stiffness. Development of such reference diagrams can help the operator to select the optimum values of TMDs' parameters for the considered wind excitation frequency.

Finally, it should be mentioned that following the same procedure proposed in this paper, TMDs' design can be implemented for other transmission lines with various excitation conditions. Similarly, the proposed PSO algorithm for the best TMDs' design can be applied in other industrial mechanisms in which the flexible cables are under the forced excitation. In this research, the linear analysis is performed for simplification.

For further studies, nonlinear development of the problem must be conducted for validating the current results. Also, for the objective of vibration suppression, the comparison of the passive method (such as those by Den Hartog) with other active control strategies or other semi-active control approaches can be pursued in future researches.

\section{Compliance with ethical standards}

Conflict of interest The authors declare that they have no conflict of interest.

\section{References}

1. Moore GF (1997) Electric cables handbook. BICC Cables Ltd, Blackwell Publishing, Wiley, Hoboken. ISBN 0-632-04075-0

2. Rawlins CB (1979) EPRI transmission line reference book, chapter 4, wind-induced conductor motion. Electric Power Research Institute, Palo Alto

3. Guile AE, Paterson W (1978) Electrical power systems, vol I. Pergamon Press, Elsevier, Amsterdam. ISBN 0-08-021729-X

4. Pansini AJ (2005) Power transmission and distribution. Fairmont Press, Lilburn. ISBN 0-88173-503-5

5. Claren R, Diana G (1969) Mathematical analysis of transmission line vibration. IEEE Trans Power Appar Syst 88(12):1741-1771

6. Simpson A (1979) Determination of the natural frequencies of multiconductor overhead transmission lines. J Sound Vib 20(4):417-449

7. Myerscough CJ (1973) A simple model of the growth of wind-induced oscillations in overhead lines. J Sound Vib 28(4):699-713

8. Braun AL, Awruch AM (2005) Aerodynamic and aeroelastic analysis of bundled cables by numerical simulation. J Sound Vib 284:51-73 
9. Wardlaw RL, Cooper KR, Ko RG, Walts JA (1974) Wind tunnel and analytical investigations into the aeroelastic behaviour of bundle conductors. IEEE PES Summer Meeting T74:367-368

10. Aboshosha H, El Damatty A (2015) Engineering method for estimating the reactions of transmission line conductors under downburst winds. Eng Struct 99:272-284

11. Rega G, Luongo A (1980) Natural vibrations of suspended cables with flexible supports. Comput Struct 12(1):65-75

12. Rega G, Vestroni F, Benedettini F (1984) Parametric analysis of large amplitude free vibrations of a suspended cable. Int J Solids Struct 20(2):95-105

13. lyengar RN, Rao GV (1988) Free vibrations and parametric instability of a laterally loaded cable. J Sound Vib 127(2):231-243

14. Soltys R, Tomko M, Kmet S (2015) Analysis of wind-induced vibrations of an anchor cable using a simplified fluid-structure interaction method. Appl Math Comput. (in press)

15. Hagedorn $P$ (1987) Wind-excited vibrations of transmission lines: a comparison of different mathematical models. Math Modell $8(C): 352-358$

16. Smith BW (1993) A review of dynamic aspects of transmission line design. Eng Struct 15(4):271-275

17. Lin WE, Savory E, McIntyre RP, Vandelaar CS, King JPC (2012) The response of an overhead electrical power transmission line to two types of wind forcing. J Wind Eng Ind Aerodyn 100:58-69

18. Hung PV, Yamaguchi H, Isozaki M, Gull JH (2014) Large amplitude vibrations of long-span transmission lines with bundled conductors in gusty wind. J Wind Eng Ind Aerodyn 126:48-59

19. Barbieri N, De Souza Júnior OH, Barbieri R (2004) Dynamical analysis of transmission line cables, part 1 linear theory. Mech Syst Signal Process 18(3):659-669

20. Darwish MM, Damatty AEl, Hangan H (2010) Dynamic characteristics of transmission line conductors and behaviour under turbulent downburst loading. Wind Struct Int J 13(4):327-346

21. Titov AA (2011) Measurement of the vibrations of the wires of electric transmission lines by a heterodyne method. Meas Tech 54(7):790-793

22. Zhou C, Liu Y, Rui X (2012) Mechanism and characteristic of raininduced vibration on high-voltage transmission line. J Mech Sci Technol 26(8):2505-2510

23. Ji K, Rui X, Li L, Leblon A, McClure G (2015) A novel ice-shedding model for overhead power line conductors with the consideration of adhesive/cohesive forces. Comput Struct 157:153-164

24. Kollár LE, Farzaneh M, Van Dyke P (2013) Modeling ice shedding propagation on transmission lines with or without interphase spacers. IEEE Trans Power Deliv 28(1):261-267

25. Ryan HM (2001) High voltage engineering and testing. Institution of Electrical Engineers, London. ISBN 0-85296-775-6

26. Ormondroyd J, Den Hartog JP (1928) The theory of the dynamic vibration absorber. Trans ASME 50:9-22

27. Dhotard MS, Ganesan N, Rao BVA (1978) Transmission line vibrations. J Sound Vib 60(2):217-237

28. Hagedorn P (1982) On the computation of damped windexcited vibrations of overhead transmission lines. J Sound Vib 83(2):253-271

29. Price SJ, Piperni $P$ (1988) An investigation of the effect of mechanical damping to alleviate wake-induced flutter of overhead power conductors. J Fluids Struct 2:53-71

30. Simpson A, Sembi PS (1984) On the use of exact modal analysis techniques in the design of damping devices for multi-conductor overhead power lines, part I: the control of aeolian vibration. J Sound Vib 97(3):357-385
31. Biswas SK, Riaz H, Ahmed NU (1987) Modal dynamics and stabilizer design for galloping transmission lines. Electric Power Syst Res 12(3):175-182

32. Markiewicz M (1995) Optimum dynamic characteristics of stockbridge dampers for dead-end spans. J Sound Vib 188(2):243-256

33. Xu YL, Yu Z, Ko JM (1998) Forced vibration studies of sagged cables with oil damper using a hybrid method. Eng Struct 20(8):692-705

34. Hijmissen JW, van den Heuvel NW, van Horssen WT (2009) On the effect of the bending stiffness on the damping properties of a tensioned cable with an attached tuned-mass-damper. Eng Struct 31(5):1276-1285

35. Cheng S, Darivandi N, Ghrib F (2010) The design of an optimal viscous damper for a bridge stay cable using energy-based approach. J Sound Vib 329(22):4689-4704

36. Li L, Cao H, Ye K, Jiang Y (2010) Simulation of galloping and wind-induced vibration control. Noise Vib Worldw 41(10):15-21

37. Liu S, Sun N, Yin Q, Qi Y, Cao D, Zhang L (2011) Study of new vibration suppression devices for application to EHV transmission line groundwires. Energy Proc 12:313-319

38. Migdalovici M, Sireteanu T, Videa EM (2010) Control of vibration of transmission lines. Int J Acoust Vib 15(2):65-71

39. Guérard S, Godard B, Lilien JL (2011) Aeolian vibrations on power-line conductors, evaluation of actual self damping. IEEE Trans Power Deliv 26(4):2118-2122

40. Asmari Saadabad N, Moradi H, Vossoughi G (2014) Semi-active control of forced oscillations in power transmission lines via optimum tuneable vibration absorbers: with review on linear dynamic aspects. Int J Mech Sci 87:163-178

41. Jiang J, Li GQ, Lu Y (2013) Vibration control of cables with damped flexible end restraint: theoretical model and experimental verification. J Sound Vib 332(15):3626-3645

42. Leung AYT, Zhang H (2009) Particle swarm optimization of tuned mass dampers. Eng Struct 31(3):715-728

43. Bekdaş G, Nigdeli SM (2017) Metaheuristic based optimization of tuned mass dampers under earthquake excitation by considering soil-structure interaction. Soil Dyn Earthq Eng 92:443-461

44. Wang L, Shi W, Li X, Zhang Q, Zhou Y (2019) An adaptive-passive retuning device for a pendulum tuned mass damper considering mass uncertainty and optimum frequency. Struct Control Health Monit 26(7):e2377

45. Shi W, Wang L, Lu Z, Wang $\mathrm{H}$ (2019) Experimental and numerical study on adaptive-passive variable mass tuned mass damper. $J$ Sound Vib 452:97-111

46. Luongo A, Zulli D, Piccardo G (2009) On the effect of twist angle on nonlinear galloping of suspended cables. Comput Struct 87(15-16):1003-1014

47. Leissa AW (1989) Closed form exact solutions for the steady state vibrations of continuous systems subjected to distributed exciting forces. J Sound Vib 134(3):435-453

48. Nocedal J, Wright SJ (2000) Numerical optimization, 2nd edn Springer, Berlin

49. Abraham A, Guo H, Liu H (2006) Swarm intelligence: foundations, perspectives and applications. In: Nedjah N, Mourelle L (eds) Swarm intelligent systems, studies in computational intelligence. Springer, New York, pp 3-25

50. Richardson AS (1990) Vibration of bundled and single conductors: a comparative case study. Electric Power Syst Res 18:19-30

Publisher's Note Springer Nature remains neutral with regard to jurisdictional claims in published maps and institutional affiliations. 